\title{
THE ADVANCES IN COMPUTER CHESS 6 CONFERENCE
}

\section{3-24 August 1990}

The conference commences at 10.30 Thursday 23 August, and will end at 4.30 Friday 24 August.

The provisional programme includes:

\section{Chunking for Experience}

Taxonomy of concepts for evaluating chess strength

Experiments with Selective Trees \& Majority Systems

A completely distributed chess program

$\alpha \beta$ conspiracy-number search

Chess databases instead of chess literature

Making dumb databases talk

Title to be announced
Jonathan Schaeffer, Michael George

Hans Berliner, Danny Kopec, Ed Northam

Ingo Althöfer

Rainer Feldman

Victor Allis, Maarten van der Meulen

Nico Kuijf, Peter van Diepen

John Roycroft

Mikhail Donskoy

Other papers on search, learning and parallelisation are anticipated for the final programme.

Registration is 30 pounds (UK pounds only please), cheques payable to "Queen Mary and Westfield College".

Accomodation is available at hotels within easy travelling distance of QMW at a variety of prices (list available on request). Single rooms are also available at QMW's student halls of residence, also within easy travelling distance of QMW, if booked by 3 August 1990. The cost is 12.50 pounds per night, including breakfast.

Please send the booking form below to: Don Beal, Department of Computer Science, Queen Mary and Westfield College, London University, Mile End Road, London E1 4NS, UK.

Registration form for Advances in Computer Chess 6, August 23-24, 1990

From: Name:

Address:

Telephone:

Please reserve QMW Halls accomodation for the night of:

(Other nights may be available on request. Please indicate nights required.)

Please circle 22 Aug 23 Aug

Please send details of hotel accomodation (tick box):

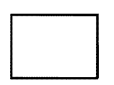

I enclose the registration fee of $£ 30 \ldots \ldots \ldots \ldots \ldots \ldots \ldots \ldots \ldots \ldots$

I enclose a QMW accomodation fee of $£ 12.50$ per night . .

I enclose total 